\title{
Assessment of the potential industrial applications of commercial dried cassava products in Nigeria
}

\author{
Wasiu Awoyale $^{1,3} \cdot$ Adebayo B. Abass $^{1,5} \cdot$ Malu Ndavi $^{2} \cdot$ Bussie Maziya-Dixon $^{1}$. \\ Michael Sulyok ${ }^{4}$
}

Received: 30 July 2016 / Accepted: 12 October 2016 / Published online: 18 October 2016

(C) The Author(s) 2016. This article is published with open access at Springerlink.com

\begin{abstract}
Variations in the functional and pasting properties of four groups of commercial dried cassava product in Nigeria were evaluated in this study, to explore their potential for use as industrial raw materials. In total, 692 products were analyzed using standard analytical methods. The functional and pasting properties of the samples were found to vary significantly $(\mathrm{p}<0.05)$. Toasted cassava was found to have the highest water absorption capacity, at $467.42 \%$, and dried cassava the lowest, at $252.57 \%$. Conversely,
\end{abstract}

Adebayo B. Abass

a.abass@cgiar.org

Wasiu Awoyale

wasiu.awoyale@kwasu.edu.ng

Malu Ndavi

m.ndavi@ifad.org

Bussie Maziya-Dixon

b.dixon@cgiar.org

Michael Sulyok

michael.sulyok@boku.ac.at

1 International Institute of Tropical Agriculture, PMB 5320 Oyo Road, Ibadan, Oyo State, Nigeria

2 Programme Management Department, International Fund for Agricultural Development, Via Paolo di Dono 44, 00142 Rome, Italy

3 Department of Food, Agriculture and Bioengineering, Kwara State University Malete, PMB 1530, Ilorin, Kwara State, Nigeria

4 Department of Agrobiotechnology (IFA-Tulln), Center for Analytical Chemistry, University of Natural Resources and Life Sciences, Vienna, Konrad Lorenzstr. 20, A-3430 Tulln, Vienna, Austria

5 International Institute of Tropical Agriculture (IITA), No. 25 Light Industrial Area, Mikocheni B, Dar es Salaam, Tanzania dried cassava was found to have the highest peak and breakdown viscosities, and toasted cassava the lowest. A significant $(\mathrm{p}<0.01)$ positive correlation was found to exist between dispersibility and the swelling power $(\mathrm{r}=-0.93)$ and solubility index $(\mathrm{r}=-0.84)$ of the cassava products. Meanwhile, the correlation between dispersibility and the peak $(r=-0.75)$ and breakdown $(r=-0.72)$ viscosities was positive and significant $(\mathrm{p}<0.05)$. Therefore, the authors of this study conclude that user industries such as the food, paper, adhesives, textiles and plywood sectors might require information on the pre-processing of cassava-based feedstock, so as to predetermine the technical usability of such raw materials within their industrial processes.

Keywords Cassava products - Processing methods · Functional properties $\cdot$ Pasting properties $\cdot$ Nigeria

\section{Introduction}

Cassava (Manihot esculenta Crantz) is grown in tropical and sub-tropical parts of the world [1] and serves as the third most important source of calories. It also constitutes about $60 \%$ of the daily calorific needs of those living in tropical and Central America [2]. Added to this, cassava plays a major role in alleviating the African food crisis, due to its availability, tolerance of environmentally stressful conditions, and its suitability for use by peasant farmers within their food systems [3, 4]. Cassava has significant potential as a food crop because it is a cheap source of calories and gives high yields per unit area. Nigeria is the largest cassava producer in the world, producing one-third more than Brazil and having almost twice the production capacity of Thailand and Indonesia [5, 6]. Despite its large production output, Nigeria is not an active participant in the international cassava market, because most of its 
cassava output is targeted at the domestic food market. As a part of this, Nigeria has not fully exploited the potential use of its cassava within the non-food industrial manufacturing sector.Author: Please check and confirm that the authors and their respective affiliations have been correctly identified and amend if necessary.Authors and their affiliation correctAuthor: Please check and confirm that the added city name is correct in the Affiliation 4.City in affiliation 4 is correct

Significant post-harvest losses of cassava roots occur in Nigeria, as a result of the root's inherent high moisture content, which accelerates microbial deterioration and undesirable biochemical changes [7]. As a result, the roots are processed, to improve their palatability, increase their shelf-life, facilitate transportation and, most importantly, detoxify the roots by removing the inherent cyanogens [8-10]. In Nigeria, cassava roots are used in food products such as gari, tapioca, lafun, fufu, starch and high-quality cassava flour (HQCF), among others. All these products differ in their functional and pasting characteristics, which are mostly influenced by the processing methods used [11-13].

The major processing features of the cassava root are its functional properties and ability to gelatinize, forming thick pastes suitable for human consumption and for use in many industrial applications. This gelatinization process is a property of the crop's starch granules [14], and such functional properties influence the end-use potential of cassava products. For instance, the granulation characteristics of milled cassava flour affect hydration rates and swelling capacities during processing [15], while color determines cassava products' visual appearance and influences the appeal of the finished products [16]. Meanwhile, the water binding and absorption capacities, swelling power and solubility of cassava have a bearing on the carbohydrate quality, viscosity and gelling ability of the flours and starches produced $[17,18]$. In addition, due to some of the undesirable properties of cassava starch, such as a breakdown in the viscosity and cohesiveness of the gelatinized starch paste, very expensive chemical and physical methods are used to improve the functionality of cassava paste for use in industrial applications. These treatments include adding heat, moisture and pressure (to enhance gelatinization temperature and lower viscosity), and also applying $\gamma$-ray treatments. Oxidation is used to lower the product's viscosity for use in making paper, while esterification is used to either lower, enhance or stabilize viscosity, and to also alter the pasting temperature. Cross-linking is also used to stabilize viscosity [19].

The ongoing expansion of cassava product utilization in Nigeria incorporates the exploitation of such products for multiple uses, taking advantage of the diverse physical and chemical properties conferred to cassava through processing, irrespective of the type of variety or genotype involved. Lately, industrial manufacturers in Nigeria such as paper mills, breweries, feed mills and ethanol plants have been exploring the use of more than one form of cassava product in their industrial processes, to reduce the impact of current monetary policies that limit access to foreign exchange for raw materials importation. However, the differences seen in the physical properties of cassava products have not previously been investigated in a single study using uniform standard scientific test methods. Therefore the aim of this study is to evaluate and compare the physicochemical properties of different processed cassava products, as a way of assessing and providing science-based evidence for their possible industrial uses beyond food.

\section{Materials and methodology}

\section{Survey and collection of commercial, dried cassava products in Nigeria}

A survey of dried cassava products traded in Nigeria was first carried out. Using a structured questionnaire, direct interviews were undertaken, to collect cassava processing information from both processors and marketers. Both dried and toasted unfermented and fermented cassava products were collected from the cassava processors and marketers. A total of 43 dried unfermented (15 cassava starches and 28 HQCF samples) and 62 dried fermented cassava products (29 lafun and $33 \mathrm{fufu}$ flour), plus 40 toasted unfermented (tapioca) and 201 toasted fermented cassava products (144 white and yellow gari samples and 57 white and yellow kpo-kpo gari samples) was collected. It is important to add that each of the cassava products collected during the survey is a representative of the sampling frame, thus, the unequal sampling size. Samples were kept in polypropylene bags and transported to the laboratory. The samples were separated into the four groups depending on the processing treatments they had been subjected to (Table 1) and were kept at $-4^{\circ} \mathrm{C}$ until the laboratory analysis was completed.

The processing methods used commercially to make the different dried cassava products are described below.

\section{Dried unfermented product}

The dried, unfermented cassava products include cassava starch and high quality cassava flour (HQCF) (Table 1). Cassava starch is produced by first peeling the cassava roots, then washing, grating, pulverizing, wet sieving, sedimenting, decanting, dewatering, drying and milling [11]. This process is similar to that for HQCF except that for HQCF the cassava roots are not pulverized, sieved or allowed to sediment before dewatering [20].

\section{Dried fermented product}

Dried, fermented cassava products include lafun and fufu flour (Table 1). The production of lafun involves peeling the cassava roots, then washing them, soaking them in water 
Table 1 Processing treatments applied to the processed, dried cassava products

\begin{tabular}{llll}
\hline Product group & Moisture removal method used & Predominant root matrix & Local name \\
\hline Dried-unfermented & $\begin{array}{l}\text { Temperature often less than } 60^{\circ} \mathrm{C} \\
\text { for starch; flash dried at } 110^{\circ} \mathrm{C}\end{array}$ & $\begin{array}{l}\text { Starch extracted through a mechanical process } \\
\text { Whole cassava matrix, containing its fiber }\end{array}$ & $\begin{array}{l}\text { Starch } \\
\text { HQCF }\end{array}$ \\
& Flash dried at $110^{\circ} \mathrm{C}$ & Starch extracted through fermentation & Fufu \\
& $\begin{array}{l}\text { Sun dried } \\
\text { Dried-fermented }\end{array}$ & Whole cassava matrix, containing its fiber & Lafun \\
Toasted-unfermented & $\begin{array}{l}\text { Temperature higher than } 200^{\circ} \mathrm{C} \\
\text { often applied }\end{array}$ & Starch extracted through a mechanical process & Tapioca \\
Toasted-fermented & $\begin{array}{l}\text { Temperature higher than } 200^{\circ} \mathrm{C} \\
\text { applied }\end{array}$ & Whole cassava matrix colored with vegetable oil & Yellow fine gari \\
& & Whole cassava matrix without vegetable oil & Yellow kpo-kpo gari (coarse) \\
& & & White fine gari \\
& & & White kpo-kpo gari (coarse) \\
\hline
\end{tabular}

(fermenting), bagging/dewatering, drying and milling the cassava [21]. Lafun is also produced by immersing peeled or unpeeled cassava roots in a stream or pool of water, or in an earthenware vessel, then fermenting them until the roots soften, after which the fermented roots are sun dried and milled into flour [21]. The production process for fufu flour is similar to that of lafun, except that for fufu flour, pulverization, and wet sieving comes after fermentation, followed by sedimentation/decantation, bagging/dewatering, granulation and flash drying [22].

\section{Toasted unfermented product}

The only cassava product in this group is tapioca (Table 1). The production of tapioca is similar to that of starch, except that toasting of the extracted starch is involved [23]. The toasting carried out here is comparable to that used for gari; however, gari is a fermented product.

\section{Toasted fermented products}

Toasted cassava products include white and yellow gari (fine gari), and white and yellow kpo-kpo gari (coarse gari) (Table 1). All the gari products are produced by first peeling the cassava roots, then washing, grating, bagging/ fermenting, dewatering, granulating, sieving and roasting them $[24,25]$. The key difference between the fine and kpokpo gari products is their particle size distribution; fine gari has a particle size of $\leq 500 \mu \mathrm{m}$, while for kpo-kpo gari it is $>1 \mathrm{~mm}$. The addition of palm oil differentiates white gari from yellow gari.

\section{Functional properties of dried cassava products}

\section{Bulk density}

This was determined using the method recommended by AOAC [26]. The sample ( $7 \mathrm{~g}$ ) was placed into a $50 \mathrm{ml}$ graduated measuring cylinder. The cylinder was then tapped gently against the palm of the hand until a constant volume was obtained, and the bulk density (BD) calculated as follows:

$\% \mathrm{BD}=\frac{\text { Weight of sample }}{\text { Volume of sample after tapping }} \times 100$

\section{Water and oil absorption capacity}

The water absorption capacity (WAC) and oil absorption capacity (OAC) were determined using the method described by Beuchat [27]. Each $1 \mathrm{~g}$ sample was mixed with $10 \mathrm{ml}$ of distilled water for WAC and $10 \mathrm{ml}$ vegetable oil for OAC and blended for $30 \mathrm{~s}$. It was then allowed to stand for $30 \mathrm{~min}$ and centrifuged at $3500 \mathrm{rpm}$ for $30 \mathrm{~min}$ at room temperature. The supernatant was decanted and the weight of water/oil absorbed by the flour calculated then expressed as WAC/OAC.

\section{Swelling power}

This was determined in accordance with the method described by Leach et al. [28], modified for small samples. A sample of $0.1 \mathrm{~g}$ was weighed into a weighed test tube, then $10 \mathrm{ml}$ of distilled water was added. The test tube was then heated in a water bath at a temperature of $60^{\circ} \mathrm{C}$ for 30 min while being continually shaken. After heating, the test-tube was centrifuged at $2200 \mathrm{rpm}$ for $15 \mathrm{~min}$ in order to facilitate the removal of the supernatant, which was then carefully decanted and the weight of the starch paste taken. The swelling power (SWP) was then calculated as:

$\%$ SWP $=\frac{\text { Weight of starch paste }}{\text { Weight of dry starch sample }} \times 100$

\section{Solubility index}

The solubility index (SI) was evaluated by placing $1 \mathrm{~g}$ of the sample into a test tube along with $20 \mathrm{ml}$ of distilled water. 
The test tube was then heated in a water bath at a temperature of $60^{\circ} \mathrm{C}$ for $30 \mathrm{~min}$. After heating, the test tube was subjected to centrifugation at $2500 \mathrm{rpm}$ for $20 \mathrm{~min} .10 \mathrm{ml}$ of the supernatant was then decanted and dried to a constant weight, with the solubility expressed as a percentage by weight of dissolved starch from the heated solution [29]. The SI was calculated as:

$\%$ SI $=\frac{\text { Weight of solubles }}{\text { Weight of sample }} \times 100$

\section{Least gelation concentration}

The method developed by Coffman and Gracia [30] was used in the determination of the Least Gelation Concentration (LGC). Appropriate sample suspensions were added to test tubes each containing $5 \mathrm{ml}$ of distilled water, to make $2-20 \%(\mathrm{w} / \mathrm{v})$ suspensions. The test tubes containing these suspensions were heated for $1 \mathrm{~h}$ in boiling water (bath) then cooled rapidly under running tap water. The test tubes were further cooled for an hour under the running water, with the LGC determined when the sample from the inverted test tube did not fall or slip.

\section{Dispersibility}

This was determined using the method describe by Kulkarni et al. [31]. The samples (10 g each) were added to a $100 \mathrm{ml}$ measuring cylinder along with distilled water, to reach a volume of $100 \mathrm{ml}$. The mixture was stirred vigorously and allowed to settle for $3 \mathrm{~h}$. The volume of the settled particles was then recorded and subtracted from 100 . The difference was then reported as percentage dispersibility.

\section{Pasting properties of dried cassava products}

The pasting characteristics of the samples were determined using a Rapid Visco Analyzer (RVA) (Model RVA-4C, Newport Scientific, Warriewood, Australia) interfaced with a personal computer equipped with the Thermocline Software supplied by the same manufacturer [32]. Each sample ( $3 \mathrm{~g}$ of moisture content; less than $12 \%$ ) was weighed into a canister and made into a slurry by adding $25 \mathrm{ml}$ of distilled water. This canister (covered with a stirrer) was then inserted into the RVA. The heating and cooling cycles were then programmed as follows. The slurry was held at $50^{\circ} \mathrm{C}$ for $1 \mathrm{~min}$, heated to $95^{\circ} \mathrm{C}$ within $3 \mathrm{~min}$ and then held at $95^{\circ} \mathrm{C}$ for $2 \mathrm{~min}$. It was subsequently cooled to $50^{\circ} \mathrm{C}$ within $3 \mathrm{~min}$ and then held at $50^{\circ} \mathrm{C}$ for $2 \mathrm{~min}$, while maintaining a rotation speed of $160 \mathrm{rpm}$. The viscosity was expressed as rapid viscosity units (RVU). The parameters determined automatically by the instrument were peak viscosity (the maximum viscosity during pasting), the breakdown viscosity (the difference between the peak viscosity and the minimum viscosity during pasting), the setback viscosity (the difference between the maximum viscosity during cooling and the minimum viscosity during pasting), the final viscosity (the viscosity at the end of the RVA run), the pasting temperature $\left({ }^{\circ} \mathrm{C}\right.$ ) (the temperature at which there was a sharp increase in the sample suspension's viscosity after the commencement of heating) and the peak time (min) (the time taken for the paste to reach peak viscosity).

\section{Statistical analysis}

Analysis of variance (ANOVA), separation of the mean values (using Duncan's Multiple Range Test at $p<0.05$ ) and Pearson correlations were calculated using Statistical Package for Social Scientists (SPSS) software (version 21.0).

\section{Results and discussion}

\section{Functional properties of the dried cassava products}

The functional properties of each of the groups of dried cassava product turned out to be significantly $(\mathrm{p}<0.01)$ different (Table 2). Among the groups, the toasted fermented cassava products had the highest WAC (467\%), swelling power (SWP) (632\%) and solubility index (SI) (4\%), but the lowest least gelation concentration (LGC) (14\%) and dispersibility $(42 \%)$. The toasted unfermented cassava products had the highest LGC (16\%) and bulk density (BD) (58\%), the dried unfermented cassava products had the highest dispersibility (74\%) but lowest WAC (233\%), and the dried fermented cassava products had the lowest BD (47\%), SWP $(325 \%)$ and SI $(2 \%)(\mathrm{p}<0.05)$ levels (Table 2$)$. This implies that toasting, which leads to partial gelatinization of the cassava root during processing, confers high WAC, SWP and SI properties on cassava. Non-gelatinized cassava products such as starch, HQCF, lafun and fufu flour maintained low WAC levels. In terms of their practical application within the industry, toasted fermented cassava products might find a use as a stabilizer in frozen products such as ice cream, owing to their high WAC. In addition, the higher SI of these products suggests that more hydrogen-bonding sites could be available for interaction with water molecules, so dissolving in adhesive mixtures and enhance their action [20]. The high SWP of toasted fermented cassava products might make them useful as thickeners and binding agents in food products, and in the non-food sector as adhesives and pastes/ glues [24]. This might also be indicative of the toasted fermented cassava products' suitability as disintegrants in the Nigerian pharmaceutical industry [33], so possibly reducing the need to import potato and corn starch [34]. The degree 


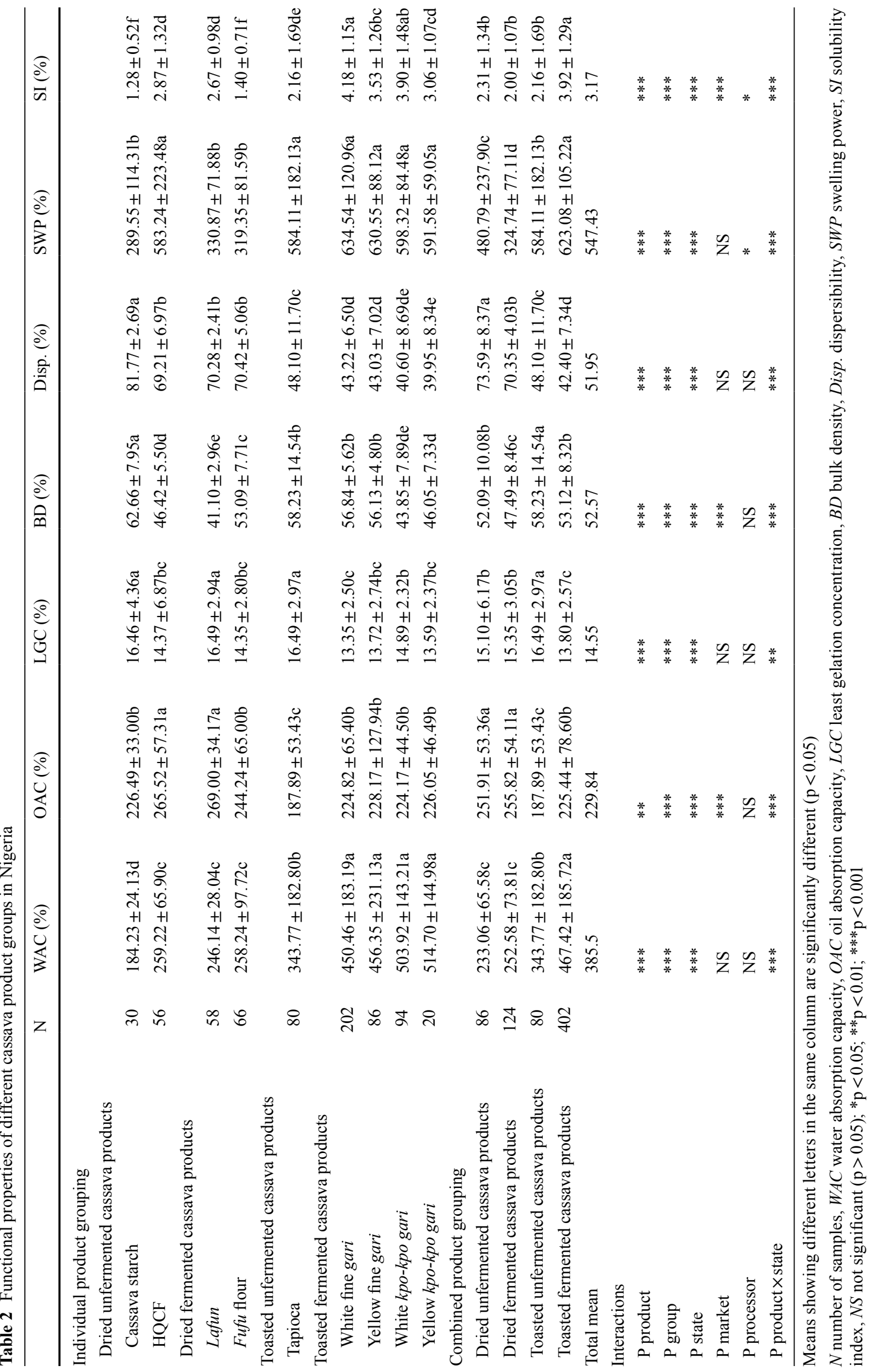


of coarseness of starchy foods is measured by its BD [35], implying that dried, fermented cassava product particles are very smooth due to their low BD levels, and so may be used as excipients in pharmaceutical tablets, in paper and in photographic paper powder, as well as cosmetic powders and laundry stiffening agents [36, 37]. Furthermore, the low BD of dried fermented cassava products could provide a smooth texture that exhibits fat mimetic properties [23] when used as a soup thickener or in ice-cream formulations. The higher the dispersibility, the better the starch flour reconstitutes in water [31]. This implies that dried unfermented cassava products with a high level of dispersibility may be suitable for applications in which a lot of starches occupy a small surface area, such as for the adsorptive removal of ions from contaminated water systems [38].

It was observed that fermentation had an increasing effect on WAC, OAC and LGC, but not to a significant degree ( $p>0.05$ ), and a decreasing effect on the BD, dispersibility, SWP and SI of the dry cassava products. Dried fermented cassava products had the highest $(\mathrm{p}>0.05) \mathrm{WAC}, \mathrm{OAC}$ and LGC values, but lower values for $\mathrm{BD}(\mathrm{p}<0.05)$, dispersibility $(\mathrm{p}<0.05)$, SWP $(\mathrm{p}<0.05)$ and SI $(\mathrm{p}>0.05)$ when compared with the dried unfermented products. The high WAC values in the fermented products observed here are corroborated by Gregory et al. [39] who reported that microorganisms usually convert carbohydrates to proteins during fermentation. Protein has been reported to be responsible for high WAC and to a lesser extent, starch and cellulose levels at room temperature [39]. Although not tested during the current study, the varieties of cassava used could influence WAC.

Within the dried fermented cassava product groups, lafun exhibited the highest OAC (269\%), LGC (16\%), SWP $(331 \%)$ and SI $(3 \%)$ levels, but lower WAC (246\%), BD $(41 \%)$ and dispersibility (70.28\%) values when compared with $f u f u$ flour, and all were significant $(\mathrm{p}<0.05)$, except for WAC, dispersibility, and SWP, which were not significant $(p>0.05)$ (Table 2). Within the dried unfermented cassava product group, HQCF produced the highest WAC (259\%), OAC $(266 \%)$, SWP $(583 \%)$ and SI (3\%) values, while cassava starch gave higher values for LGC (16\%), BD $(63 \%)$ and dispersibility $(82 \%)(\mathrm{p}<0.05)$. The WAC, OAC and SWP values for cassava starch shown here are higher than those seen by Ikwegwu et al. [40], but the SI value for the cassava starch reported by Ikwegwu et al. [40] was higher than in this study. In addition, the WAC and OAC values for HQCF reported by Ikwegwu et al. [40] were lower than those seen in this study. The high WAC values as seen for $f u f u$ flour and HQCF in their respective groups may be attributed to their higher dietary fiber content; as this increases their ability to hold water combined with the loose structure of their starch polymers, while the low values seen in lafun and cassava starch might indicate lower dietary fiber content levels and compactness in their starch molecular structures, as both are more starchy than fufu and HQCF [22, 41]. In addition, the high OAC values seen for lafun and HQCF are typical for food ingredients that retain flavor in food after having been cooked into a paste. The higher the LGC, the higher the amount of starch needed to form a gel [42] meaning only a small quantity of $f u f u$ flour and HQCF may be needed to form a gel due to their low LGC, and this means they may be used economically, since less will be required to make food gels. Further, $f u f u$ flour and cassava starch may be easily reconstituted during food preparation, and might also mix easily with other food ingredients, both due to their high dispersibility [30].

Toasted, fermented cassava products had higher WAC, OAC, SWP and SI values, but lower values for LGC, BD, and dispersibility $(p<0.05)$ when compared with unfermented toasted products. Within the toasted fermented cassava products group, white fine gari had the highest BD $(57 \%)$, dispersibility $(43 \%)$, SWP $(635 \%)$ and SI $(4 \%)$ values, while yellow kpo-kpo gari had the lowest values for these parameters, but with higher WAC (515\%) levels. The high WAC value shown for yellow kpo-kpo gari implies that its starch structure is more loosely bound together than white fine gari, which has a low WAC [41]. The OAC was higher in yellow fine gari (228\%) but lower in white kpo-kpo gari (224\%) while the LGC value was higher for white kpo-kpo gari $(15 \%)$ than for white fine gari $(13 \%)$. However, most of these parameters were not significant $(\mathrm{p}>0.05)$ (Table 2). The high OAC value for the yellow fine gari could be attributed to a high affinity for oil shown by gari, which already has red palm oil added to [23]. Sanni et al. [24] reported similar values closer to that of the SI and BD of the gari products in this study, when researching the properties of gari used in Lagos State.

Furthermore, when comparing the fermented and unfermented products based on the methods used to dry them, dried fermented cassava products exhibited high OAC, LGC and dispersibility levels, but low WAC, BD, SWP and SI values when compared to toasted fermented cassava products. This means that fermentation followed by toasting might have a larger increasing effect on the WAC level than fermentation and dry in the sun, or than when using pneumatic dryers. The dried unfermented cassava products revealed high OAC, dispersibility, and SI levels when compared to the toasted unfermented cassava products, which had higher WAC, LGC, BD and SWP levels (Table 2). The effect of starch granular integrity might also be responsible for the significant $(\mathrm{p}<0.05)$ negative correlation $(\mathrm{r}=-0.68)$ that was found to exist between WAC and the breakdown viscosity of the cassava products (Table 4 ).

This study also found a significant $(\mathrm{p}<0.01)$ negative correlation $(\mathrm{r}=-0.78)$ between LGC and setback viscosity (Table 4). This implies that the higher the LGC, the lower 
the setback viscosity and the more stable the cooked gel might be. Thus, dried cassava products with higher LGC in their respective groups may have a greater potential to produce a stable gel when cooked [23]. Furthermore, a significant $(\mathrm{p}<0.01)$ positive correlation was found between dispersibility and the swelling power $(\mathrm{p}<0.01 ; \mathrm{r}=-0.93)$ and solubility index $(\mathrm{r}=-0.84)$ of the cassava products. Meanwhile, the correlation between dispersibility and the peak $(r=-0.75)$ and breakdown $(\mathrm{p}<0.05 ; \mathrm{r}=-0.72)$ viscosities was positive and significant (Table 4$)$.

\section{Pasting properties of dried cassava products}

In view of the fact that all the dried cassava products will be cooked in hot water (except gari which may also be eaten having been soaked in cold water) before use in industrial applications, the pasting properties of the products are important in predicting their behavior during and after cooking. The results here reveal that processing methods (products) had a significant effect $(\mathrm{p}<0.001)$ on the pasting properties of all the cassava product groupings (Table 3 ). However, there was a significant difference $(\mathrm{p}<0.05)$ found in the peak, trough and setback viscosities of the products in different groups. For breakdown viscosity and peak time, though, there was no significant difference $(p>0.05)$ found between the toasted fermented and unfermented cassava products. Similarly, the dried fermented and unfermented cassava products were found to show no significant difference $(p>0.05)$ in terms of their pasting temperatures. In addition, the dried fermented and toasted fermented cassava products were not significantly different $(p>0.05)$ in their final viscosities (Table 3). Between these two groups, dried unfermented cassava products revealed the highest peak (496 RVU) and breakdown (315 RVU) viscosities, while the dried fermented cassava products had the highest trough (198 RVU) and final (290 RVU) viscosities. Toasted fermented cassava products had the highest setback viscosity $(117 \mathrm{RVU})$ and pasting temperature $\left(78^{\circ} \mathrm{C}\right)$, but the toasted unfermented cassava products displayed the lowest values for all the pasting properties, except for peak time which was high (6 min) (Table 3$)$. The high peak viscosity shown by the dried unfermented cassava products indicates a weak granular structure for its starch when compared to those products with a low peak viscosity [43]. As a result, the dried unfermented cassava products might be inferior to the other cassava products when applied to textiles, due to their high breakdown viscosity. This viscosity may be rapidly lowered on heating under shear, leading to a long and cohesive paste texture, which is something not wanted when applied to textiles [44].

Furthermore, the high final viscosity exhibited by dried fermented cassava products makes them suitable for many food products, such as sauces, soups, and dressings, and also in the textiles industry and during the paper making process, where high viscosities are required [45]. Meanwhile, the low final viscosity of toasted unfermented cassava products makes them suitable for paper surface applications, those in which a lower viscosity and a good film forming capacity are preferred [45]. The differences observed in setback viscosity levels among the cassava product groups reflect the different thermodynamic behaviors of these products during heating, something which might play an important role in their industrial application. The low setback viscosity of toasted unfermented cassava products results in the formation of a more stable paste viscosity during processing, making them useful in several industries, including textiles. In contrast, the high setback viscosity exhibited by toasted fermented cassava products might limit their use in the food and textile industries [44]. The temperature at which the first detectable viscosity is measured in an amylogram is the pasting temperature, which is a reflection of the swelling of the starch paste and is affected by the starch concentration level [44]. The low pasting temperature of toasted unfermented cassava products suggests they may form pastes more easily than other products, and so may be more suitable for food and non-food industrial processes because of the reduced energy costs incurred. However, the variation seen in pasting temperatures among the different cassava products offers a wide range of options in terms of their utilization in the industrial sector [44].

In this study, and regarding the effect of fermentation on the dried products, dried fermented cassava products tended to show the highest trough, final and setback viscosities, and also peak time levels $(\mathrm{p}<0.05)$, but also lower peak and breakdown viscosities $(\mathrm{p}<0.05)$, and pasting temperatures ( $p>0.05$ ), when compared to the unfermented cassava products. Within the dried fermented cassava product group; fufu flour had the highest peak time ( $5 \mathrm{~min}$.), pasting temperature $\left(75^{\circ} \mathrm{C}\right)$, and trough $(216 \mathrm{RVU})$, as well as final (331 RVU) and setback (115 RVU) viscosities when compared to lafun, which had higher peak (466 RVU) and breakdown (287 RVU) viscosity values. The peak time and the final and setback viscosities obtained in the fufu flour were comparable to those of the rotary and flashed dried fufu flour products studied by Sanni et al. [46]. Among the dried unfermented cassava products groups, HQCF had the highest of all the pasting properties $(p<0.05)$ when compared with cassava starch (Table 3).

In addition, the toasted fermented cassava products had higher values for all the pasting properties $(\mathrm{p}<0.05)$ (excluding breakdown viscosity), except for peak time, which was lower but not to a significant degree $(p>0.05)$ when compared with the toasted unfermented cassava products. The values obtained for the tapioca's pasting properties were lower than those reported by Adebowale et al. [47], except for peak time and pasting temperature, which were 


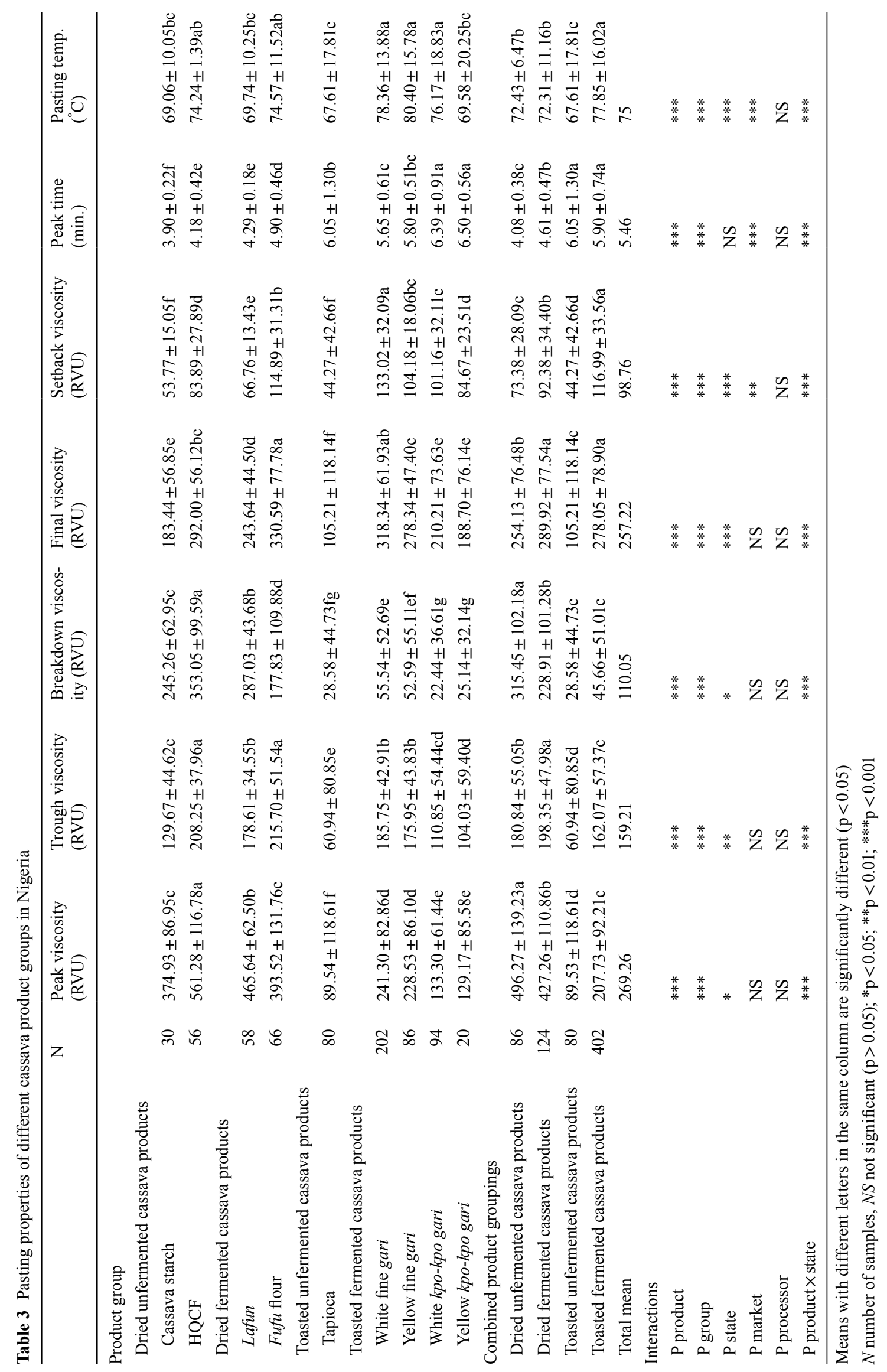




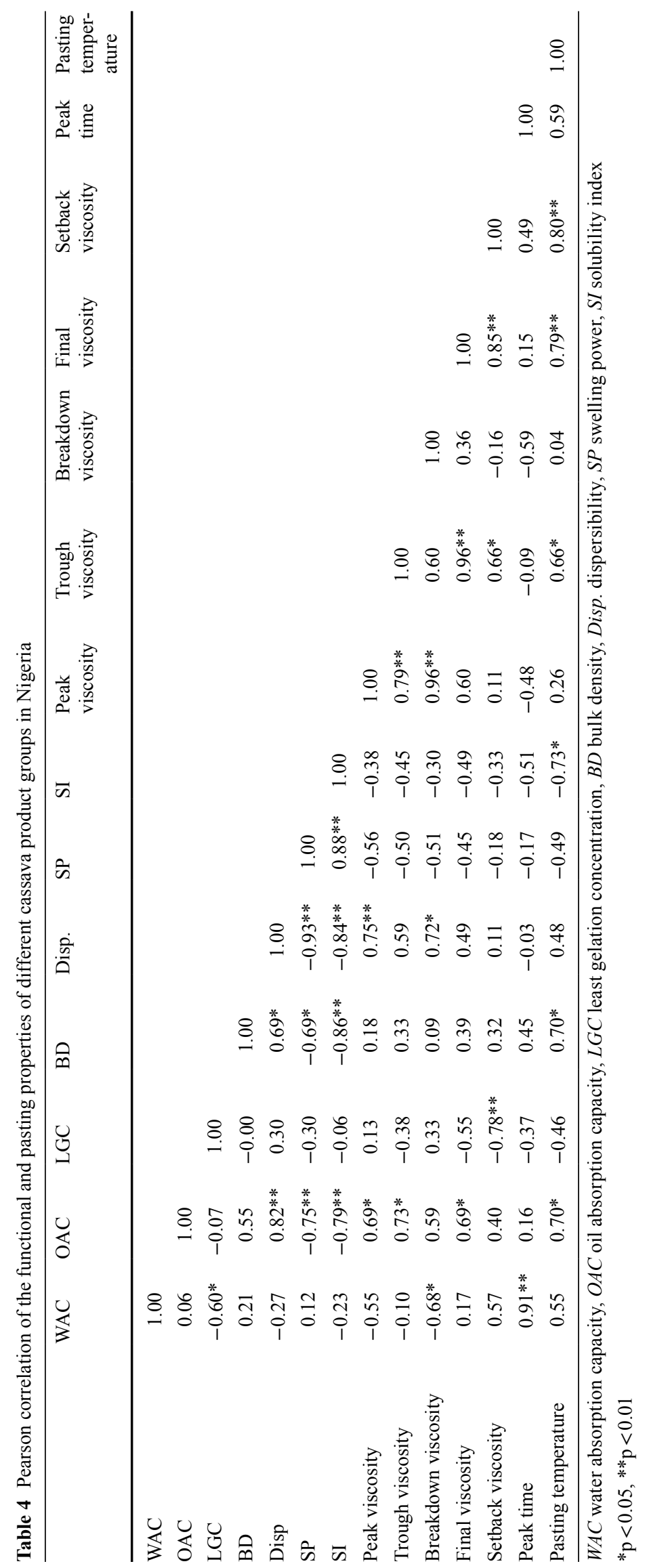


higher. This could be attributed to varietal differences and processing methods. Concerning the toasted fermented cassava products, white fine gari revealed the highest pasting property levels, except for peak time $(5.65 \mathrm{~min})$ and pasting temperature $\left(78^{\circ} \mathrm{C}\right)$, which were higher in the yellow kpo$k p o$ and fine gari (Table 3). All the pasting properties of the gari reported by Sanni et al. [24] were in the same range as found in this study, except for breakdown viscosity which was lower in this study, and the peak time and pasting temperature levels, which were higher.

Furthermore, when comparing the fermented and unfermented products based on the drying methods used, dried fermented cassava products were found to have a higher peak, trough, breakdown and final viscosities than the toasted fermented cassava products, which instead had higher setback viscosity, peak time and pasting temperature levels. All these properties were significant $(\mathrm{p}<0.05)$, except for final viscosity $(p>0.05)$. The pasting properties were significantly $(\mathrm{p}<0.05)$ higher in the dried unfermented cassava products, but lower for peak time when compared to those of the toasted unfermented cassava products (Table 3).

The temperature at the onset of any rise in viscosity is referred to as the pasting temperature (PTp) [46]. The PTp is also a measure of the minimum temperature required to cook a given food sample, which has implications for the stability of other components in a formulation and gives an indication of the energy costs incurred during such a process [31]. In this study, all the cassava products were ready, having been cooked at an average temperature of $75^{\circ} \mathrm{C}$, for less than $7 \mathrm{~min}$, so conserving energy during the cooking process. This was because their PTp is below the boiling point of water. The HQCF, fufu flour, and white fine gari could; therefore, be used in industrial applications such as plywood and paperboard manufacturing due to their high peak viscosity (PV), as this requires a good paste to be produced with moderately high gel strength [48]. Adebowale et al. [49] observed that the higher the breakdown viscosity (BDV) of a starchy material, the lower is its ability to withstand heating and shear stress during cooking. Therefore, tapioca, white kpo-kpo gari and lafun may withstand heating and shear stress during cooking because of their low BDV levels (Table 3). In this study, it was also observed that for the toasted fermented products, the coarse nature of the kpo-kpo gari might have contributed to the low BDV values seen, as there was significant difference $(p<0.05)$ between fine and coarse kpo-kpo gari products in terms of their BDV values, even when palm oil was added.

Additionally, a product with a lower final viscosity (FV) has a lower tendency to retrograde, meaning cassava starch, tapioca, yellow kpo-kpo gari and lafun might retrograde $[21,25,45]$. However, fufu flour, white gari, and HQCF might retrograde faster after cooking due to their high setback viscosities (SBVs). This might seem obvious, given the significant $(\mathrm{p}<0.01)$ negative correlation $(\mathrm{r}=-0.78)$ between SBV and LGC observed in this study (Table 3). In addition, it was also observed that the PTp value increased as the solubility index fell. This is because a significant $(p<0.05)$ negative correlation exists between PTp and the solubility index $(r=-0.73)$ (Table 4$)$. The high dispersibility of HQCF could be responsible for its high PV, due to the fact that in this study a significant $(\mathrm{p}<0.01)$ positive correlation $(\mathrm{r}=0.75)$ was found to exist between PV and dispersibility (Table 4).

\section{Conclusion}

The results of this study show that cassava products can vary significantly in terms of their functional and pasting properties, as a result of the different processing methods used to produce them. In this study, toasted fermented cassava products were found to have the highest water absorption capacities, as well as swelling power and solubility index levels. Dried unfermented cassava products; meanwhile, had the lowest water absorption capacities, and dried fermented cassava products had the lowest swelling power and solubility index levels. Dried unfermented cassava products exhibited a high peak and breakdown viscosities, while dried fermented cassava products revealed high trough and final viscosities. Toasted unfermented cassava products had the highest setback viscosity and pasting temperature levels, but the toasted fermented cassava products had the lowest of all the pasting property values, except for peak time. Therefore, manufacturing industries intending to use cassava products, such as those in the food, paper, adhesives, textiles and plywood making sectors, should seek information on the pre-processing of cassava-based feedstock, so as to predetermine the technical usability of the raw materials applied in their industrial processes.

Acknowledgments The authors would like to acknowledge the International Fund for Agricultural Development and the Root, Tuber and Banana Project for their assistance with this work.

\section{Compliance with ethical standards}

Conflict of interest No conflict of interest is reported.

Open Access This article is distributed under the terms of the Creative Commons Attribution 4.0 International License (http://creativecommons.org/licenses/by/4.0/), which permits unrestricted use, distribution, and reproduction in any medium, provided you give appropriate credit to the original author(s) and the source, provide a link to the Creative Commons license, and indicate if changes were made. 


\section{References}

1. M.M. Burrell, Starch: the need for improved quality or quantity, an over view. J. Exp. Bot. 218, 4574-4762 (2003)

2. S.C. Kobawila, D. Louembe, S. Keleke, J. Hounhouigan, C. Gamba, Reduction of the cyanide content during fermentation of cassava roots and leaves to produce bikedi and ntoba mbodi, two food products from Congo. Afr. J. Biotechnol. 4(7), 689-696 (2005)

3. J.A. Montagnac, C.R. Davis, S.A. Tanumihard, Nutritional value of cassava for use as a staple food and recent advances for improvement. Compr. Rev. Food Sci. Food Saf. 8(3), 181-194 (2009)

4. B. Maziya-Dixon, A.G.O. Dixon, A.A. Adebowale, Targeting different end uses of cassava: genotypic variations for cyanogenic potentials and pasting properties. Int. J. Food Sci. Technol. 42, 969-976 (2007)

5. T.P. Phillips, D.S. Taylor, L.O. Sanni, M.O. Akoroda, A cassava industrial revolution in Nigeria: the potential for a new industrial crop. The global cassava development strategy. (IFAD/FAO, Rome, 2004)

6. FAOSTAT, Database (2008), http://faostat.fao.org. Accessed 30 Sep 2009

7. C.A. Onyenwoke, K.J. Simonyan, Cassava post-harvest processing and storage in Nigeria: a review. Afr. J. Agric. Res. 9(53), 3853-3863 (2014)

8. G.N. Iwuoha, G.G. Ubeng, U.I. Onwuachu, Detoxification effect of fermentation on cyanide content of cassava tuber. J. Appl. Sci. Environ. Manag. 17(4), 567-570 (2013)

9. A. Westby, Cassava utilization, storage and small-scale processing, in Cassava Biology, Production and Utilization, ed. by R.J. Hillocks, J.M. Thresh, A.C. Bellotti (CABI Publishing, Wallingford, 2002), pp. 281-300

10. D.B. Nyirenda, L. Chiwona-Karltun, M. Chitundu, S. Haggblade, L. Brimer, Chemical safety of cassava products in regions adopting cassava production and processing - Experience from Southern Africa. Food Chem. Toxicol. 49, 607-612 (2011)

11. L.O. Sanni, M. Onitilo, O.B. Oyewole, A.O. Dipeolu, K. Adebayo, I.A. Ayinde, K. Tomlins, A. Wesby, Effect of Cassava varieties and processing methods on the qualities of starch in Southwest Nigeria. Paper presented at the Food Africa, Yaounde, Cameroon, 2003

12. M.O. Onitilo, L.O. Sanni, O.B. Oyewole, B. Maziya-Dixon, Physicochemical and functional properties of sour starches from different cassava varieties. Int. J. Food Prop. 10, 607-620 (2007)

13. H.A. Etudaiye, T.U. Nwabueze, L.O. Sanni, Pasting and functional properties of fufu processed from cassava mosaic disease resistant varieties cultivated in a high rainfall zone. Niger. Food J. 27(2), 185-193 (2009)

14. T. Sánchez, D. Dufour, I.X. Moreno, H. Ceballos, Comparison of pasting and gel stabilities of waxy and normal starches from potato, maize, and rice with those of a novel waxy cassava starch under thermal, chemical, and mechanical stress. J. Agric. Food Chem. 58, 5093-5099 (2010)

15. D.W. Hatcher, G.G. Bello, M.J. Anderson, Flour particle size, starch damage, and alkali reagent: impact on uniaxial stress relaxation parameters of yellow alkaline noodles. Cereal. Chemistry 86, 361-368 (2009)

16. D. MacDougall, Color in Food: Improving Quality. Woodhead Publishing Series in Food Science, Technology and Nutrition. No. 75, Wood-head (Woodhead publishing, Cambridge, 2002), p. 392

17. L.L. Niba, M.M. Bokanga, F.L. Jackson, D.S. Schlimme, B.W. $\mathrm{Li}$, Physicochemical, properties and starch granular characteristics of flour from various Manihot esculenta (Cassava) genotypes. J. Food Sci. 67(5), 1701-1705 (2002)
18. O.O. Oladunmoye, A.U. Ozumba, O.B. Oluwole, C.O. Orishagbemi, H.M. Solomon, O. Olatunji, Development of process technology for cassava-based noodle products. J. Sci. Eng. Technol. 11, 5705-5717 (2004)

19. T. Premkumar, G. Padmaja, S. Moorthy, S.K. Nanda, M. George, C. Balagopalan, New cassava products of future potential in India, in Cassava's potential in Asia in the 21th century: present situation and future research and development needs. Proceedings of the 6th Regional Workshop held in Ho Chi Minh City, Vietnam, February 21-25, 2000. IAS, CIAT, The Nippon Foundation, ed. by R.H. Howeler, S.L. Tan (2001)

20. N.A. Drakwa, F.K. Jetuah, D. Sekyere, Utilization of cassava flour for production of adhesive for the manufacture of paperboards. Final report 3 on the sustainable industrial markets for cassava project output 2.2 .2 , p. 16 (2003)

21. A.M. Ogunnike, P.A. Adepoju, A.O. Longe, G.N. Elemo, O.V. Oke, Effects of submerged and anaerobic fermentation on cassava flour (lafun). Afr. J. Biotechnol. 14(11), 961-970 (2015)

22. A.A. Olapade, Y.O. Babalola, O.C. Aworh, Quality attributes of fufu (fermented cassava) flour supplemented with bambara flour. Int. Food Res. J. 21(5), 2025-2032 (2014)

23. B.O. Otegbayo, F.O. Samuel, T. Alalade, Functional properties of soy-enriched tapioca. Afr. J. Biotechnol. 12(22), 3583-3589 (2013)

24. L.O. Sanni, A.A. Adebowale, W. Awoyale, G.O. Fetuga, Quality of gari (roasted cassava mash) in Lagos State, Nigeria. Niger. Food J. 26, 125-130 (2008)

25. S.O. Nwancho, F.C. Ekwu, P.O. Mgbebu, C.K. Njoku, C. Okoro, Effect of Particle Size on the Functional, Pasting and Textural Properties of Gari Produced from Fresh Cassava Roots and Dry Chips. Int. J. Eng. Sci. 3(3), 50-55 (2014)

26. Association of official analytical chemists (AOAC), Official Methods Of Analysis of the Association of Official Analytical Chemists, 17th edn. (AOAC, Washington, DC, 2000)

27. L.R. Beuchat, Functional and electrophoretic characteristic of succinylated peanut flour. Agric. Food Chem. 25, 258-261 (1977)

28. H.W. Leach, D.L. McCovwen, T.J. Schoch, Swelling and solubility patterns of various starches, structure of granules. Cereal Chem. 36, 534-544 (1959)

29. K. Kainuma, T. Odat, S. Cuzuki, Study of starch phosphates monoesters. J. Technol. Soc. Starch 14, 24-28 (1967)

30. C.W. Coffman, V.V. Garcia, Functional properties and amino acid content of protein isolate from mung bean flour. J. Food Technol. 12, 473-484 (1977)

31. K.D. Kulkarni, D.N. Kulkarni, U.M. Ingle, Sorghum malt-based weaning food formulations: preparations, functional properties and nutritive value. Food Nutr Bull 13(4), 322-327 (1991)

32. Newport Scientific, Applications manual for the Rapid viscoTM analyzer using thermocline for windows. (Newport Scientific Pty Ltd., Warriewood, 1998), pp. 2-26

33. K.P.R. Chowdary, V. Enturi, Preparation, characterization and evaluation of starch citrate. A new modified starch as a disintegrant in tablet formulations. Int. J. Pharm. Res. Dev. 12, 9-17 (2011)

34. G.G. Doue, R. Megnanou, E.M. Bedikou, L.S. Niamke, Physicochemical characterization of starches from seven improved cassava varieties: Potentiality of industrial utilization. J. Appl. Biosci. 73, 6002-6011 (2014)

35. A.O. Ashogbon, Physicochemical properties of Bambara groundnut starch and cassava starch blends. Afr. J. Food Sci. 8(6), 322 329 (2014)

36. N. Singh, N. Inouchi, K. Nishinari, Structural, thermal and viscoelastic characteristics of starches separated from normal, sugary and waxy maize. Food Hydrocoll. 20, 923-935 (2006)

37. N. Singh, L. Kaur, K.S. Sandhu, J. Kaur, K. Nishinari, Relationships between physicochemical, morphological, thermal, 
rheological properties of rice starches. Food Hydrocoll. 20, 532$542(2006)$

38. J. Eke-Ejiofor, F. Owuno, The functional properties of starches, physico-chemical and sensory properties of salad cream from cassava and potatoes. Int. J. Nutr. Food Sci. 3(6), 567-571 (2014)

39. C.C. Ahaotu, C.I. Ogueke, Owuamanam, N.N. Ahaota, J.N. Nwosu, Fermentation of undewatered cassava pulp by linamarase producing microorganisms: effect on nutritional composition and residual cyanide. Am. J. Food Nutr. 3(1), 1-8 (2013)

40. O.J. Ikegwu, V.N. Nwobasi, M.O. Odoh, N.U. Oledinma, Evaluation of the Pasting and Some Functional Properties of Starch Isolated from some Improved Cassava Varieties in Nigeria. Afr. J. Biotechnol. 8, 2310-2315 (2009)

41. J.O. Anyango, H.L. de Kock, J.R.N. Taylor, Evaluation of the functional quality of cowpea-fortified traditional African sorghum foods using instrumental and descriptive sensory analysis. LWT Food Sci. Technol. 44, 2126-2133 (2011)

42. J. Eke-Ejiofor, Functional properties of starches, physico-chemical and rheological properties of glucose syrup made from cassava and different potato varieties. Int. J. Recent Sci. Res. 6(6), 4400-4406 (2015)

43. A. Aprianita, U. Purwandari, B. Watson, T. Vasiljevic, Physicochemical properties of flours and starches from selected commercial tubers available in Australia. Int. Food Res. J. 16, 507-520 (2009)

44. R. Mufumbo, Y. Baguma, S. Kashub, E. Nuwamanya, P. Rubaihayo, S. Mukasa, B. Hamaker, S. Kyamanywa, Functional properties of starches on the East African market. Afr. J. Food Sci. 5(10), 594-602 (2011)

45. S.N. Moorthy, Physicochemical and functional properties of tropical tuber starches. Starch/Starke 54, 559-592 (2002)

46. L.O. Sanni, A.A. Adebowale, T.A. Filani, O.B. Oyewole, A. Westby, Quality of flash and rotary dried fufu flour. J. Food Agric. Environ. 4(3\&4), 74-78 (2006)

47. A.A. Adebowale, L.O. Sanni, F.O. Ladapo, Chemical, functional and sensory properties of instant yam-breadfruit flour. Niger. Food J. 26(1), 2-12 (2008)

48. A.A. Adebowale, L.O. Sanni, A. Kuye, Effect of roasting methods on sorption isotherm of tapioca grits. Electron. J. Environ. Agric. Food Chem. 5(6), 1649-1653 (2006)

49. A. Adebowale, L.O. Sanni, S.O. Awonorin, Effect of texture modifiers on the physicochemical and sensory properties of dried fufu. Food Sci. Technol. Int. 11(5), 373-382 (2005) 